\title{
OS SERMONES VARIOS ATRIBUÍDOS AO PADRE ANTÔNIO VIEIRA (1662 - 1678): LIVREIROS E LEITORES
}

Ana Elisa Silva AREDES

\begin{abstract}
RESUMO
Este artigo tem por objetivo analisar o processo de produção das edições de sermonários do padre Antônio Vieira impressas em Madrid, entre 1662 e 1678. Parte da pesquisa de doutoramento, este trabalho pretende perceber para quais leitores esses livros, intitulados Sermones Varios del Padre Antonio de Vieyra, de la Compañia de Jesus, eram direcionados. Para isso, consideramos a materialidade dos volumes e as relações interpessoais construídas entre os agentes do livro, ou seja, entre aqueles que participaram da elaboração, da produção e da circulação dos impressos, bem como eles agiram na aplicação e na sujeição direta aos regulamentos que governavam o ofício do livro. A fim de cumprirmos nossas intenções, recorremos aos instrumentos fornecidos pela perspectiva da História do livro e das práticas de leitura para nos auxiliar a compreender, analisar e interpretar as informações que encontramos nas fontes históricas. Ao partir da análise das edições madrilenas, este trabalho busca, em documentos de diversas naturezas, informações sobre agentes associados ao mercado livreiro-editorial que envolveu a circulação desses livros.
\end{abstract}

PALAVRAS-CHAVE: Antônio Vieira; História do livro; práticas de leitura; mercado livreiro-editorial; jesuítas.

\section{THE SERMONES VARIOS ATTRIBUTED TO FATHER ANTÔNIO VIEIRA (1662 - 1678): MERCHERS AND READERS}

\section{ABSTRACT:}

This article will aim to investigate the process of producing sermons editions, printed in Madrid, between 1662 and 1678, which is attributed to priest Antônio Vieira. Part of the doctoral research, this paper intends to understand for whon thoes books were intended, entitled Sermones Varios del Padre Antonio de Vieyra, de la Compañia de Jesus,. For this, we will consider the books's materiality and the interpersonal relationships built between the book agentes. In order to fulfill our intentions, we fetch the perspective of books history and reading practices to understand, analyze and interpret the information that is found in historical sources. Having the starting point in the Madrid editions, this work seeks in documents of various natures information about agents connected in the editorial market.

KEYWORDS: Antônio Vieira; Book's history; reading practices; book's market; jesuits.

\section{LOS SERMONES VARIOS ATRIBUIDOS AL PADRE ANTÔNIO VIEIRA (1662-1678): COMERCIANTES Y LECTORES}

\section{RESUMEN:}

Este artículo tiene como objetivo analizar el proceso de producción de las ediciones de los sermones del padre Antônio Vieira impresas en Madrid, entre 1662 y 1678, que el jesuita identificó al reunir sermones corruptos y extraterrestres. Como parte de la investigación doctoral, este trabajo pretende comprender a qué lectores se dirigieron estos libros, titulados Sermones Varios del Padre Antonio de Vieyra, de la Compañia de Jesus. Para eso, consideramos la materialidad de los libros y las relaciones interpersonales construidas entre los agentes del libro. Para cumplir con nuestras intenciones, utilizamos las herramientas proporcionadas por la perspectiva de la Historia del libro y las prácticas de lectura para ayudarnos a comprender, analizar e interpretar la información que encontramos en las fuentes históricas. A partir del análisis de las ediciones de Madrid, este trabajo busca en documentos de diversas naturalezas información sobre agentes involucrados en el mercado de producción y publicación de libros.

PALABRAS CLAVE: Antônio Vieira; Historia del libro; prácticas de lectura; mercado de libros; jesuitas.

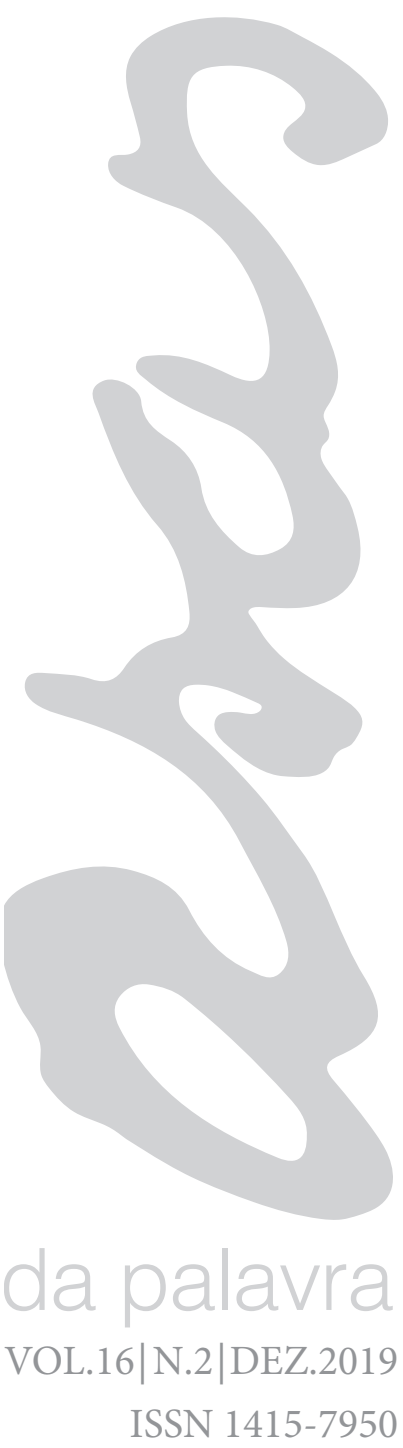




\section{INTRODUÇÃO}

A proposta da História do livro e das práticas de leitura repousa na compreensão do funcionamento das práticas editoriais, de escrita e de recepção. Partindo das assertivas de Arthur Anselmo (1997, p.17), percebemos que para reconstruir as trajetórias do livro, da produção à recepção, o historiador deve interrogar sobre o processo de fabricação, sobre a época em que foi escrito e publicado e como o livro circulou nos anos seguintes. Essa perspectiva abre espaço para a análise da leitura como um fenômeno social. Ao recorrer a Víctor Infantes, percebemos que escrever a História das práticas de leitura trata-se de investigar "as modalidades, as práticas e os usos, assim como as circunstâncias e [...] os efeitos [...] da leitura, dentro de um processo plurissecular de incorporação (ou de não incorporação) da cultura escrita e impressa" (INFANTES, 2003, p.18). Aliado a isso, e apoiado no trabalho de Micheal de Certeau (1998), pode-se afirmar que a existência e a circulação de um livro não indicam, por si só, o que ele significa para os leitores, fazendo-se necessário analisar as formas que os leitores leem, interpretam e mobilizam o texto.

Partindo dessa perspectiva, este artigo, que é parte de uma

1 Este trabalho é resultado da pesquisa de doutorado que está a ser realizada no momento. 'canonizacão' literária do Padre Antônio Vieira: os circuitos do livro na Europa e nas Américas (c.1662 - c.1920)", tem como um dos objetivos estudar os modos de produção, circulação e recepção dos textos atribuídos a Vieira.
VOL. 16 | N.2 | DEZ.2019 ISSN 1415-7950 pesquisa em andamento ${ }^{1}$, analisará o processo de produção dos três primeiros volumes de sermonários do padre Antônio Vieira impressos em Madrid, os quais foram intitulados Sermones Varios del Padre Antonio de Vieyra, de la Compañia de Jesus. Desse modo, nosso objetivo é perceber quem eram os leitores que esses livros pretendiam atingir, levando em consideração que a produção, a circulação e a recepção dos livros dependiam dos espaços de sociabilidade e de negociação que eram ocupados pelos agentes envolvidos na economia do livro e, portanto, interessados na comercialização ou no recolhimento das edições em questão.

Considerando que o livro reúne representações de práticas culturais referentes às épocas de sua escrita e de sua publicação, procederemos metodologicamente com questões voltadas aos usos e funções dos elementos que compõem os livros recolhidos e consultados. Nesse sentido, baseamos nossa escolha de adotar procedimentos referentes à arqueologia do objeto no fato de que o livro é um objeto cultural e a materialidade do texto conforma a recepção, isto é, a construção do significado do texto depende da forma com que ele se apresenta ao leitor (CHARTIER, 2014, p.20). 
A nível metodológico, nossas questões se voltaram, em especial, para os paratextos e para os recursos tipográficos mobilizados nas edições. A partir dessas indagações, coletamos informações e mapeamos os agentes do livro envolvidos na produção e na circulação dos Sermones Varios. Uma vez identificados os agentes, recorremos a documentos de naturezas diversas ao buscar compreender as relações que envolviam a Companhia de Jesus, Antônio Vieira, os livreiroseditores, os tradutores, os censores e as autoridades encarregadas de examinar os textos. Buscar vestígios das ações e as relações sociais construídas por esses agentes faz-se necessário uma vez que, além da existência do texto, os ofícios editoriais e gráficos e o setor comercial eram fatores determinantes para a circulação e, portanto, para o acesso ao livro.

\section{ESTRATÉGIAS COMERCIAIS E EDITORIAIS: A CIRCULAÇÃO DOS SERMONES VARIOS}

$\mathrm{Na}$ bibliografia especializada, as referidas edições impressas em Madrid são conhecidas pelas críticas elaboradas por Vieira em Leitor, texto que abre o primeiro volume dos Sermoens da editio princeps (1679). Segundo a advertência que Vieira faz aos leitores, uma das razões que o persuadiram a organizar e a publicar os seus sermões em livros impressos foi a profusão de textos, tanto manuscritos quanto impressos, que ora atribuíam a ele discursos de outrem, ora publicavam textos de sua autoria escritos de forma corrompida, uma vez que eram extraídos somente da memória da audiência. Mobilizando esse argumento, Vieira legitima a impressão dos seus sermões, que deveriam ser publicados em doze volumes, reunindo textos que, à época, já circulavam por escrito, os quais estariam na editio "restituídos à sua original inteireza" (VIEIRA, 1679, n.p.).

Ainda no primeiro volume da editio princeps, Antônio Vieira lista os textos reunidos nos três volumes impressos em Madrid, sendo o primeiro, impresso em 1662, com 7 sermões e 3 discursos, todos reconhecidos por Vieira como de sua autoria; o segundo, impresso em 1664, com 22 sermões, sendo 10 considerados de autoria alheia; e o terceiro, impresso em 1678, com 18 sermões e 1 questão, a qual o autor afirma ser alheia, assim como 13 dos sermões. Essas edições serão analisadas neste trabalho, assim como a reimpressão do primeiro volume, datada de 1664, e a reimpressão do segundo, datada de 1678. 
Apesar de o padre Vieira ser identificado como autor no frontispício dos volumes de Sermones Varios, não parece que o jesuíta tenha aprovado, consentido ou tido notícia das publicações no período em que corriam os processos de petição e concessão das licenças, aprovações e censuras. Vale lembrar que, na Espanha, as práticas tipográficas foram submetidas a formas de controle que se estenderam por todo o processo de edição, da recolha de impressos que circulavam até a revisão de originais (GOMEZ, 2003, p.101). Conforme a imprensa revolucionava o modo de transmissão de conhecimento, os poderes régios e eclesiásticos desenvolveram um sistema censório dedicado a regular a impressão e a circulação de livros, a fim de evitar a profusão de ideias hostis às suas instituições e ao conjunto de valores morais que reproduziam.

Apesar do desconhecimento e da posterior desaprovação de Vieira, as três partes dos Sermones adequavam-se às determinações legais e passaram pelo sistema censório espanhol sem maiores dificuldades. Respeitando às determinações da Pragmática dos livros promulgada por Felipe II, em 1558, os volumes passaram pelo Conselho real e pela avaliação do escrivão da Câmara, além de reunirem, no princípio do livro, o título, o nome do autor, a licença, a tassa, o privilégio, o nome do impressor e o local de impressão.

Tendo isso em vista, Vieira relata a Duarte Ribeiro de Macedo, em carta datada de 23 de maio de 1679, que pediu ao Santo Ofício que recolhesse os exemplares de Sermones Varios, os quais contêm sermões "totalmente alheios e supostos", corrompidos e mal traduzidos (VIEIRA, 1928, p.392). Portanto, Vieira teve que se valer de sua influência para pedir o recolhimento dos volumes.

Contudo, constatamos que a solicitação de Vieira não foi atendida pelos inquisidores. Por um lado, encontramos os volumes em bibliotecas espalhadas pela Europa e Américas, como o caso da reimpressão do tomo segundo dos Sermones, que, em 1745, encontrava-se no acervo do Colégio dos Jesuítas em Praga, no famoso Clementinum. Por outro, na Espanha, o Édito inquisitorial de 17 de março de 1776 expurgou as expressões "de que Jesu-Christo adoró al Demonio, y à Judas" (Conselho, 1776, p.1) que constam nos fólios 105 e 113, do segundo volume Sermones Varios (1664; 1678). A expressão expurgada corresponde ao Sermão do Primeiro Domingo da Quaresma, pregado na cidade de São Luís, em 1653, 
e é acusada, no Édito, de blasfêmia. Portanto, se foi expurgado em 1776, a segunda parte de Sermones Varios não poderia ter sido recolhida antes e, tendo Vieira requerido a recolha dos três títulos usando os mesmos argumentos e na mesma ocasião, não poderiam os inquisidores aprovar a recolha de um título sem que aprovassem a recolha dos demais.

Em relação às estruturas de poder e de controle social vigentes nas monarquias europeias ibéricas, o fato dos Sermones Varios permanecerem em circulação, apesar do desagrado público de Vieira, fortalecia a estrutura censória pela qual os volumes foram submetidos e aprovados. Por se ter estabelecido um processo burocrático-administrativo que delimitava a permissão ou a proibição da impressão de textos, o livro reunia, em suas primeiras páginas, informações sobre a sua produção e a sua distribuição. Nesse sentido, percebemos que o livro era constituído de um conjunto de materiais heterogêneos, com diferentes origens e funções, as quais indicam diversas relações entrelaçadas ${ }^{2}$. Estampados depois da impressão do texto, os materiais preliminares e finais do livro reúnem e articulam "um conjunto complexo de relações com o poder que vai bem além da estratégia de uma influência sobre o público, uma influência que [...] está a serviço de uma melhor recepção para o texto e uma leitura mais pertinente do mesmo" (CHARTIER, 2014, p.240).

Ao analisarmos os paratextos das edições dos Sermones varios, observamos que os livros foram impressos com o financiamento de dois mercadores de livros madrilenos, os quais comercializaram os títulos em suas lojas. O mercador de livros Lorenzo de Ibarra custeou três edições: aquela que viria ser a primeira (1662), intitulada Sermones Varios del Padre Antonio de Vieyra, de la Compañia de Jesus; a Segunda parte (1664) e a reimpressão da primeira (1664). Em 1678, a Terceira Parte e a reimpressão da Segunda foram custeadas por Gabriel de León.

Com as informações que constavam nos frontispícios das edições, localizamos os endereços das lojas em que os mercadores Lorenzo de Ibarra e Gabriel de León vendiam os livros em Madrid. Lorenzo de Ibarra tinha uma loja na Calle de Toledo, ao lado do Colégio da Companhia de Jesus; enquanto Gabriel de León possuía loja na Puerta del Sol, em frente ao convento de São Felipe. A localização geográfica das lojas nos indica dois locais em que circulavam os livros e os ambientes comerciais em que estavam inseridos.
2 Materiais como as dedicatórias, privilégios, aprovações, licenças, censuras, suma de tassa, erratas, notícias prévias e textos ao leitor.

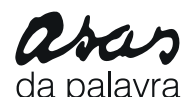

da palavra 

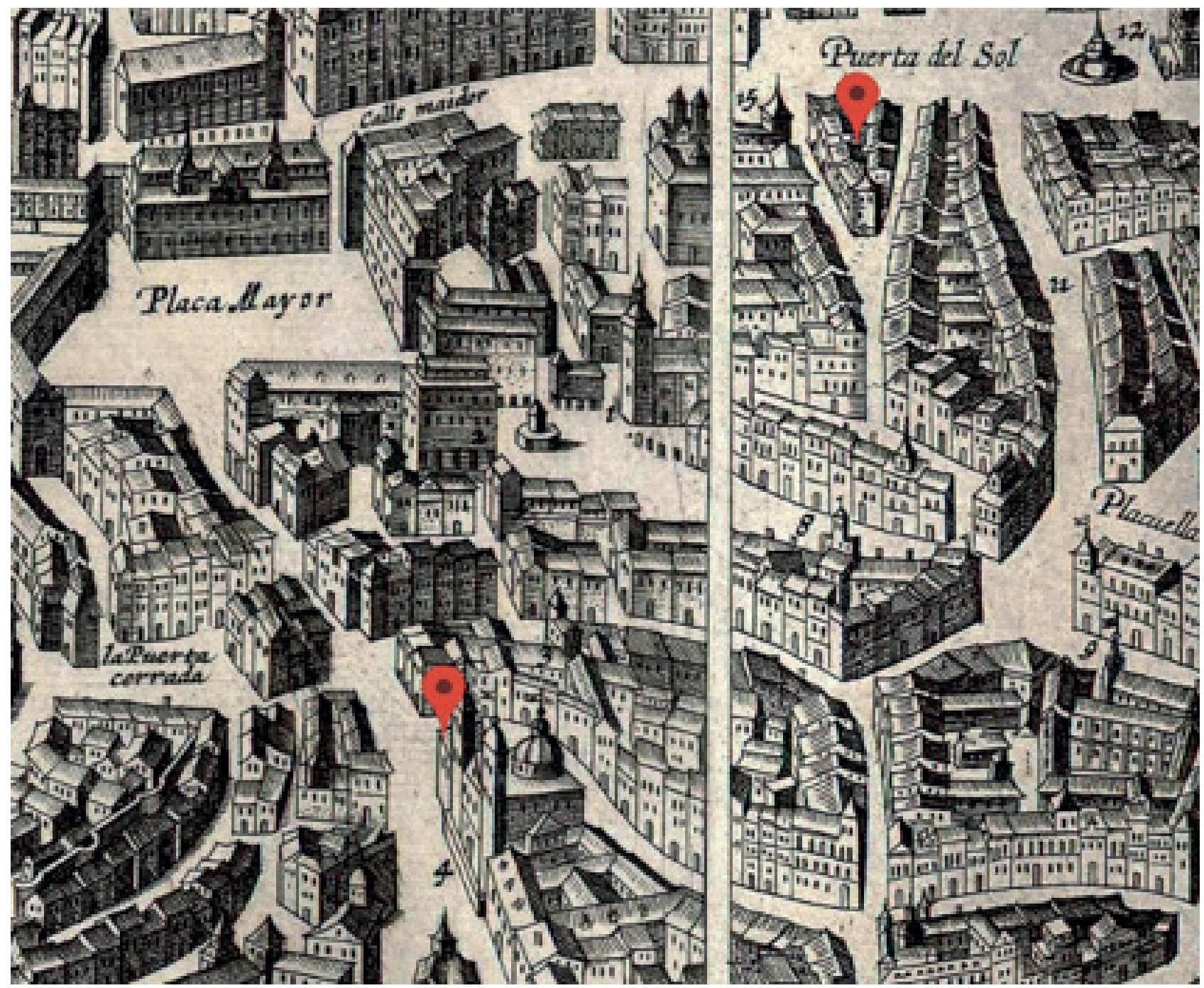

FIGURA 1: Detalhe no Mapa de Madrid. Com os pins, indicamos as localizações das lojas de Gabriel de León, na Puerta del Sol (pin do lado direito) e de Lorenzo de Ibarra, Calle de Toledo (pin do lado esquerdo). Detalhe extraído do mapa La Villa de Madrid Corde de los Reys Católicos de España (Anonymous, 1657?).

De acordo com Mercedes Agulló y Cobo (1991), entre a segunda metade do século XVI e a primeira metade do século XVII, os mercadores de livros de Madrid se concentravam na Calle de Santiago. No entanto, durante a segunda metade do século XVII, observa-se que muitos profissionais do livro se estabeleceram na Calle de Toledo. Como destaca a autora, o Colégio Imperial da Companhia de Jesus se tornou o centro cultural de maior importância de Madrid, o que levou livreiros, impressores, fundidores e encadernadores para os seus arredores, concentrando-se na Calle de Toledo (COBO, 1991, p.34).

Entre 1662 e 1677, Lorenzo de Ibarra manteve sua única loja de livros na mesma rua que seu sogro, Francisco de Robles, livreiro 
de Jesus - assim como havia feito o seu pai, o mercador de livros Sebastián de Robles, entre 1612 e 1630 - (COBO, 1991, p.270). As "covachuelas" era uma espécie de porão com acesso à rua, sendo localizado abaixo do "Estudio de la Compañía", que, durante o século XVII, alugou constantemente suas lojas a livreiros e a impressores. Lorenzo de Ibarra, em 1669, casou-se com Maria de Robles, que era viúva de Gabriel Jiménez, mercador de cera e livreiro eventual. Pelo matrimônio, Ibarra, que era filho de um pequeno mercador de livros, inseriu-se em uma extensa família de impressores, de livreiros e de encadernadores.

Assim como Francisco, muitos dos membros da família de Robles eram vizinhos de Ibarra, como os livreiros Jeronima de Robles e Juan Antonio Bonet, respectivamente prima e tio de Maria de Robles. Ibarra foi também vizinho de Pablo do Val, impressor da primeira edição dos Sermones Varios (1662). Segundo Jaime Moll (2013, p.489), entre 1652 e 1653, Pablo do Val morou em frente ao Colégio da Companhia de Jesus e, em 1654, mudou-se para a Calle de la Encomienda.

Já Gabriel de León, o maior livreiro madrileno do século XVII, manteve mais de uma loja no decorrer de suas atividades como mercador de livros ${ }^{3}$. Gabriel começou a trabalhar como livreiro aos 15 anos e, com o tempo, mudou o endereço de suas lojas com alguma frequência, tendo se fixado, por último, na Puerta del Sol. Nesse endereço, sua loja possuía uma localização privilegiada, pois estava localizada em frente ao convento de São Felipe, local de intensa atividade comercial.

Durante o século XVII, assim como os jesuítas do Colégio, os agostinhos de São Felipe decidiram arrendar as "covachuelas" do convento. Como demonstrou Sanchez Espinosa (2001), esses espaços atraíram muitos comerciantes e, a partir da ocupação dessas lojas, São Felipe se transformou em um ponto de referência em Madrid no que dizia respeito às atividades comerciais. Desse modo, São Felipe atraiu muitos mercadores de livros, que vendiam os textos em postos no entorno do edifício, como livrarias a céu aberto.

Pouco antes de morrer, Gabriel de León publicou o Catalogo de los libros que tiene Gabriel de León, Mercader de Libros en esta Corte (1688), com os livros e papéis impressos que existiam em sua livraria. Seus herdeiros continuaram o negócio após Gabriel
3 Em 1640, Gabriel de León tinha uma livraria na Calle de Toledo e, na mesma época, comprou uma casa a Melchior Medina, na Calle Mayor. Em 1645, comprou as casas de Catalina de Villada, na Calle Mayor, esquina com a Calle da Paz e junto às grades de São Felipe. Também teve loja em uma das casas de María Cisneros, em frente à Calle de la Paz, e na Puerta del Sol. No entanto, como relembra Infantes e Pereira (2012), a Puerta del Sol e a Calle Mayor são citadas indistintamente nos documentos de livreiros e impressores, podendo, em alguns casos, tratar-se das mesmas casas.

4 Nos escudos xilográficos usados nos livros custeados por Gabriel de León havia um leão e um escudo com as inicias GDL. Após sua morte, seus herdeiros continuaram a usar esse emblema. A primeira ocorrência que identificamos do escudo com as iniciais PDL é no livro de Martin de Torrecilla, Alegatos, apologias y consultas varias, volume III, impresso em 1697. No entanto, os escudos com as iniciais GDL continuaram a ser usados após essa data, como em 1702, na reimpressão do primeiro volume de Alegatos. 
5 Esse levantamento foi realizado a partir dos dados apresentados por Pereira e Infantes (2012), do catálogo de Gabriel de León (1688) e da consulta dos catálogos da Biblioteca Nacional da España, Biblioteca de la Universidad Complutense de Madrid; Biblioteca de Sevilla; Biblioteca da Universidade de Barcelona; Biblioteca Nacional do México.

6 Encontramos três ediç̃es custeadas pela viúva de Lorenzo de Ibarra, a saber: Reyno de Dios compendio y medula de toda la Corte Santa, de Nicolas Caussin (1677); Sermones varios, de Antonio de Céspedes (1677); Sermones varios, de Jacinto Barrasa (1678). ISSN 1415-7950

falecer, em 1688. Em 1697, é possível identificar Pedro de León, filho de Gabriel, como pelo menos um dos "Herderos de Gabriel de León", uma vez que, nesse ano, foram acrescentadas as iniciais de Pedro no escudo xilográfico impresso no frontispício dos livros ${ }^{4}$. No entanto, Pedro de León já trabalhava como mercador de livros décadas antes do falecimento do pai. Entre 1660 e 1664, Pedro viveu em Lima, onde manteve trato com os negócios de Gabriel de León, recebendo caixas de livros remetidas de Madrid por seu pai e cuidando de pagamentos em nome de seu pai (LEÓN, 1991, p.302).

Irmãos da Hermandad de Libreiros, Lorenzo de Ibarra e Gabriel de León mantiveram suas livrarias em ambientes de intensa circulação de livros em Madrid, o principal centro tipográfico da Espanha no século XVII. Importante notar que, segundo Manuel Peña Díaz (2003), na primeira metade do século XVI, livreiros e impressores migraram de Sevilha para as capitais do Vice-Reino da Nova Espanha (Cidade do México) e do Vice-Reino do Peru (Lima) e, assim, fortaleceram Sevilha como centro de distribuição de livros, ao passo que, contribuíram para que grandes livreiros de cidades castelhanas controlassem as redes comerciais que direcionavam livros para as Américas. Desse modo, a principal rota comercial de livros percorria Alcalá de Hernares, Madrid, Toledo, Sevilha e Américas. Portanto, percebemos que Ibarra e León poderiam estar ligados a essas redes comerciais, hipótese que, como veremos a seguir, já possui indícios de confirmação.

Além disso, ao realizarmos um levantamento das edições custeadas por cada livreiro 5 , confirmamos que os "livros religiosos" representam a maioria das publicações, assim como, entre os autores eclesiásticos, os jesuítas são maioria: nas edições custeadas por Gabriel de León, de 128 autores, 84 eram religiosos, dos quais conseguimos localizar as ordens religiosas de 61. Dessas edições, 19 são textos de autores jesuítas, que, em número, são seguidos pelos franciscanos, que somam 10 autores. Nas edições custeadas por Lorenzo de Ibarra, todos os autores eram religiosos, no total 14, sendo 8 jesuítas. Esse fato ressalta as relações de proximidade construídas entre Lorenzo de Ibarra e os padres da Companhia de Jesus, as quais se estenderam à sua esposa, que, após sua morte, custeou a impressão de três livros, todos de autoria de padres jesuítas ${ }^{6}$.

Quanto aos livros custeados por León, dos 21 sermonários impressos, 10 foram publicados na década de 1670 e 7 foram 
REVISTA DO PROGRAMA DE PÓS-GRADUAÇÃO EM COMUNICAÇÃO, LINGUAGENS E CULTURA DA UNIVERSIDADE DA AMAZÔNIA

publicados na década de 1680. Assim, observamos que o interesse de Gabriel em custear sermonários foi maior nas décadas em que financiou as impressões dos Sermones de Vieira. Já para Ibarra, os dois livros atribuídos a Vieira representam metade dos sermonários custeados por ele, sendo 3 sermonários publicados entre 1662 e 1664. Poderíamos perceber esse dado como uma tendência similar ao caso de León, no entanto isso implicaria desconsiderar que, no mercado livreiro-editorial da Espanha, León gozava de maior poder financeiro e prestígio que Ibarra e, portanto, possuía um amplo campo de escolhas em relação aos livros que poderia custear. Por conseguinte, é preciso ter em consideração o volume de edições que cada livreiro se envolveu, bem como o tempo ao qual cada um se dedicou à atividade de editor-livreiro. Nesse sentido, é importante sublinhar que Gabriel atuou como livreiro por 53 anos e Lorenzo por 13.

Desse modo, a investigação sobre os mercadores León e Ibarra aponta para o fato de que, apesar de Vieira não ter concordado com a elaboração dos três primeiros volumes de Sermones Varios, religiosos da Companhia de Jesus estavam associados aos livreiros que custearam esses livros. Portanto, questionamo-nos qual seria o público que esses comerciantes tinham em questão para a venda dos volumes de Sermones Varios. No entanto, para a formulação dessa indagação, devemos ter em vista que a leitura do sermão, originalmente proferido pelo pregador no púlpito, constituía um novo locutor e um novo destinatário e, portanto, produz uma nova situação comunicativa que insere o texto em outro contexto sócio-histórico (MENDES, 1989, p.308).

Ao recorrer à análise da estrutura desses livros, percebemos que trazem Índices de lugares da Escritura e listas dos Assuntos e coisas notáveis. Organizados pelo tradutor Don Estevan de Aguilar y

7 Máxima latina mobilizada por Vieira no Sermão do Beato Estanislau, de 1674, e no Sermão do Nascimento do Menino Jesus, 1633. Poeta nasce, orador se faz. Zuñiga, esses índices foram impressos após a impressão dos sermões, sendo inseridos nos sermonários como estratégia editorial, a fim de direcionar o livro aos oradores sacros e aos noviços de ordens religiosas. Vale fazer uma rápida digressão a fim de destacar que D. Estevan era um distinto teólogo que assistia em Madrid e foi o tradutor, do português para o castelhano, das duas partes de Laurea lusitana (1679) e, do latim para o castelhano, de Los Tártaros en China (1665) e La Corte Divina (1675), sendo o primeiro impresso à custa de Gabriel de León e os dois últimos à custa de Lorenzo de Ibarra. ISSN 1415-7950

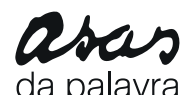

da palavra 
Desse modo, os índices funcionariam como apoio para a confecção de cadernos de lugares comuns e como instrumento para o leitor retornar a leitura dos sermões impressos em busca de questões e autoridades específicas. Tendo em vista que poeta nascitur orador fit", na operação retórica da inventio, o "leitor-orador" poderia recorrer aos Sermones Varios para a construção de uma pregação homilética. Em consonância com as funções dos índices, os impressores inseriram nas margens direitas e esquerdas, que circundavam os sermões, as referências das citações latinas. Assim, esses recursos tipográficos foram desenvolvidos para direcionar as publicações a um público, interessado na identificação e na localização das expressões latinas retiradas da Bíblia e dos textos de autoridades clássicas e escolásticas, adequando a materialidade do livro às expectativas dos seus destinatários.

Essas práticas editoriais estavam associadas ao modo de ler douto. É necessário dizer que, antes da publicação dos sermonários em Madrid, alguns sermões atribuídos a Vieira tinham sido impressos sob o formato de folhetos. Impressos em Lisboa, Coimbra, Évora, Madrid, Saragoça, Valência, Milão, Roma e Nápoles, cada um desses folhetos continham um texto parenético, sendo que os publicados em castelhano e italiano correspondiam a sermões pregados originalmente nessas línguas. No entanto, em oposição ao que acontecia com os folhetos e folhas soltas em que sermões eram impressos, a materialidade dos Sermones Varios direcionava os leitores para a leitura silenciosa e introspectiva. Diferente à teatralização oral do sermão, a leitura silenciosa, que ocupava os gabinetes de leitura dos colégios e universidades, difundiuse pelas cortes e aristocracias seculares; enquanto a leitura em voz alta, que envolvia todos os gêneros literários, integrava a vida social cortesã e fazia-se presente na leitura de textos aos analfabetos (CHARTIER, 2003, p.143).

A terceira parte dos Sermones Varios possui um índice dos sermões publicados, ausente nas edições anteriores. Portanto, a sistematização dos sermões em uma lista, que organiza o conteúdo do livro, confirma as relações entre as edições dos Sermones Varios, a leitura douta e a intenção do uso dos livros para a formação do orador. Ao acrescentar o índice dos sermões, o livreiro-editor Gabriel de León chama atenção do leitor para as matérias de cada sermão publicado no volume, possibilitando que o leitor recorra a um texto específico sem a necessidade de folhear o livro. 
Sendo Vieira conhecido, nas décadas de 1660 e 1670, como um grande pregador português de seu tempo, seus sermões eram procurados nas Américas e na Europa por religiosos de diversas ordens, mas principalmente pelos jesuítas. Identificamos a demanda dos padres jesuítas por textos de Vieira em algumas missivas enviadas ao Procurador Geral da Província de Portugal, padre João de Almeida. Em carta de 21 de março e em outra de 8 de julho de 1674, o padre del Vale pediu ao padre Almeida que enviasse à Província do Peru alguns sermões de Vieira impressos em Portugal, fazendo referência aos folhetos que mencionamos (VALE, 1674, f.1). Questionamos, então, se as edições dos Sermones Varios estariam associadas a uma demanda dos colégios jesuítas espalhados na Península Ibérica e nas Américas. Para buscar uma resposta à questão, estudaremos os inacianos que foram associados aos Sermones Varios na Delação do Conde de Tarouca.

Transcrita por Fernando Bouza Álvarez, a Delação de Duarte Luís de Menezes, Conde de Tarouca, datada de 16 de fevereiro de 1662, é uma denúncia ao Conselho de Castela sobre a intenção de se imprimir em Madrid os sermões de Antônio Vieira, os quais atentariam "contra a monarquia de Felipe IV" (MENEZES, 1997, p.142). Segundo Álvarez (2000), D. Duarte Luís de Menezes, após a aclamação de D. João IV, fugiu para a Espanha pelo Norte de África, acompanhado por seus dois filhos e por outros nobres portugueses. Teria chegado a Ayamonte em um barco de remos e se dirigiu à Corte para prestar fidelidade a Felipe IV. Foi penalizado em Portugal, assim como os referidos nobres, tendo os seus bens confiscados e seus rendimentos consignados ao provimento dos embaixadores portugueses. Em Castela, D. Duarte, em 1641, recebeu o título de Marquês de Penalva como recompensa à fidelidade que prestou a Felipe IV.

Retornando à Delação, percebemos que as datas da Aprovação (5 de fevereiro de 1662) e a da Licença (11 de fevereiro de 1662) da primeira parte dos Sermones são anteriores à data da Delação; e a Suma da Tassa e a Fé de Erratas foram obtidas 5 meses depois da licença, o que não indica uma interrupção do processo de impressão. Portanto, na época da escrita da Delação, os sermões e discursos impressos na primeira parte dos Sermones Varios já haviam sido analisados pelos censores, que aprovaram o livro e, portanto, não identificaram nada que agredisse o poder monárquico espanhol. 
8 O referido Pedro de Pantoja foi mencionado na carta de poder outorgada por Diego García de Cáceres em favor de Pantoja e de Antonio Lozano, 19 de abril de 1559 (JARA, 1996, p.49-50).
Na Delação, os padres jesuítas Juan de Ribadeneira, identificado como "procurador da província do Peru", e Pedro de Pantoja, "procurador da província do Novo Reino", são mencionados como aqueles que pretendiam imprimir o sermonário de Vieira, identificado como "predicador que fue del rebelde de Portugal". A apresentação desses jesuítas como incentivadores da impressão dos sermões corrobora a hipótese de que a proximidade entre o impressor Lorenzo de Ibarra e religiosos jesuítas poderia ter garantido as licenças e o privilégio real, viabilizando a impressão dos livros sem que o suposto autor aprovasse ou sequer tivesse conhecimento.

Chama a atenção, entretanto, o fato de Juan de Ribadeneira, em 1664, ter recebido uma licença de envios de livros de Madrid para Lima, para que se remetesse 100 caixas de livros (Conselho, 1664, f.312). Os títulos desses livros foram listados em uma petição apresentada ao Conselho, que, ao aprová-los, permitiu que fossem enviados em caixas seladas, sendo conferidos no porto de Lima por agentes do Santo Ofício.

Em contrapartida, ao tentar localizar Pedro de Pantoja, não encontramos qualquer registro, com exceção de um escrivão espanhol do cabido da Conceição, em $1559^{8}$. No entanto, por meio da descrição do Conde de Tarouca, encontramos o padre jesuíta Alonso de Pantoja, procurador da província do Novo Reino, em 1662, a quem a reimpressão da primeira parte dos Sermones Varios (1664) é dedicada.

O padre Alonso de Pantoja teve uma longa carreira em colégios jesuítas nas Américas. Ele atravessou o Atlântico na expedição de 1631 e, em 1634, encontrava-se em terras americanas, onde ensinou Retórica e Filosofia no Colégio de Quito. Entre 1639 e 1642, Pantoja foi reitor do Seminário de São Luis e, em 1644, ajudou a fundar a residência de Ibarra, tornando-se reitor do Colégio da Vila de São Miguel de Ibarra, localizada a 72 km de Quito. Entre 1653 e 1658, foi diretor do colégio-seminário de São Bartolomeu, onde lecionou teologia. Segundo José Fajardo (2007), Alonso de Pantoja se tornou procurador em 1658, sendo antes suplente do procurador Joaquín de Amestoy, e foi reitor do Colégio de Quito entre 1664 e 1666. Por fim, entre 1668 e 1672, padre Alonso foi reitor da escola de Las Nieves e, entre 1673 e 1692, foi Procurador Geral das Índias.

Como reitor, Pantoja elaborava pedidos de livros enviados a seus superiores jesuítas em Madrid e, quando agraciado com o benefício, recebia-os nos portos americanos. Em 1666, o então reitor Alonso de 
Pantoja recebeu quarenta caixas com "livros, medalhas e coisas de devoção" que saíram da Espanha a bordo do navio de Santo Cristo da Boa Viagem (Conselho, 1666, f.1).

Os dados colhidos sobre Alonso de Pantoja e Juan de Ribadeneira apontam que os Sermones Varios teriam como destino o mercado da América Hispânica e, em especial, os colégios da Companhia de Jesus. As cargas de livros recebidas pelos padres jesuítas mostram o envolvimento direito de Pantoja e Ribadeneira com o comércio de livros transatlântico, de Madrid para as Américas.

Além disso, os cargos de reitor ocupados por Alonso de Pantoja indicam intenções em relação à aplicação dos Sermones no ensino, principalmente no Colégio de Quito. Essa questão, em especial, nos chamou atenção após a leitura do Memorial do Pedro de Contreras, religioso do Colégio Imperial da Companhia de Jesus (1625). Nesse documento, padre Contreras (1625, f.2) discute a importância da imprensa para o ensino jesuítico e a necessidade da flexibilização da concessão de privilégios para livros que eram aplicados no ensino dos Colégios da Companhia ${ }^{9}$.

Assim como no caso de Pantoja, as dedicatórias dos Sermones Varios se voltaram para agentes envolvidos no trânsito atlântico. O livro publicado em 1662 foi dedicado a Blas Canales de Carrança, capelão maior, advogado fiscal da Câmara do Arcebispado de Toledo e juiz subdelegado nas Canárias. A reimpressão da segunda parte (1678) foi dedicada ao Padre Francisco de Aguiar y Seixas, Bispo de Mechoacan, conhecido por ser inimigo de Sor Juana Inês e admirador de Vieira, tendo se envolvido na publicação de alguns textos desse pregador no México. Já a terceira parte (1678) foi dedicada ao Padre Frei Nicolas de Alcocer, administrador do Novo Rezado Eclesiástico na Espanha e no Novo Mundo, pelo Convento Real de Escorial, sendo, portanto, responsável pela correção de livros litúrgicos.

A dedicatória contribuía para introduzir o leitor ao texto e o prepara para uma leitura apropriada (Cayuela, 1996). Como espaço narrativo e oferta de dádiva a qual não se espera rejeição, a dedicatória pode ser analisada como uma doação entre ausentes, em que o autor ou livreiro transmite o livro ao receptor. Representação dos atos de dar e receber, a dedicatória se insere no sistema de privilégios como estratégia tanto voltada para o público quanto para a benevolência do protetor. Com intenções de explorar o mercado atlântico, os
9 Padre Pedro (1625, f.2) defende o privilégio perpétuo da Imprensa Real para a impressão dos clássicos (os quais lista no memorial) e sugere uma nova abordagem para a concessão de privilégios nos Reinos de Castela, Aragão e Portugal (cada conselho despacharia autores naturais e os registraria nos outros conselhos). 
mercadores Lorenzo de Ibarra e Gabriel de León mobilizaram a fama e o prestígio de Vieira nas dedicatórias, a fim de legitimar as impressões dos sermões e direcionar os livros para os leitores doutos.

Portanto, os paratextos não estavam simplesmente em busca de uma melhor recepção, uma vez que não funcionavam somente como espaço estratégico para influenciar o público. Fossem de natureza administrativa, encomiástica, performativa ou biográfica, os paratextos eram unidos, de modo a enunciar e articular um conjunto complexo de relações com os poderes da Coroa e da Igreja (CHARTIER, 2014, 245). Para Anne Cayuela (1996), além de serem construídos por manifestações de controle teológico-político sobre a produção impressa, os paratextos funcionam como espaços em que se teatralizavam e se reproduziam as hierarquias sociais. Nesse sentido, além de revelar as relações pessoais que envolviam e condicionavam a produção e a circulação dos livros, os paratextos são discursos que proporcionavam o encontro entre o texto e o leitor, em que se atesta a utilidade do texto para o público e comprova a autoridade do autor, sem deixar de apresentá-lo e representá-lo.

A partir dessa análise, podemos perceber que os volumes dos Sermones Varios estavam associados à formação dos pregadores e, sobretudo, daqueles que frequentavam os colégios jesuítas. Nesse sentido, nota-se que a maior parte dos censores nomeados para emitir juízos sobre os Sermones Varios eram jesuítas que assistiam no Colégio Imperial da Companhia de Jesus, do qual, como mencionado, era vizinho o mercador Ibarra.

Da primeira parte do sermonário, foi censor o jesuíta Agustín de Castro que, conhecido por frequentar os círculos cortesãos espanhóis, foi pregador real durante o reinado de Felipe IV, ocupou a cátedra de Política no Colégio Imperial entre 1630 e 1646 e firmou a aprovação de obras de grande fama, como Nápoles recuperada (1649) e Obras Varias Poeticas de Don Geronimo Cancer y Velasco (1661). Da segunda parte dos Sermones Varios, foram censores os jesuítas Juan Manuel Ramirez e Juan Antonio Velazquez, sendo este, na altura da emissão da aprovação, provincial de Castela e, anteriormente, reitor dos colégios de Monforte, Segovia, Medina del Campo, Valladolid e Salamanca, sucessivamente. Por fim, da terceira parte, os censores foram religiosos de outras ordens: o oratoriano Doutor Baltasar Fajardo, prepósito da Casa de São Felipe Neri de Madrid, e o bernardino Frei Baltasar de Figueroa, pregador real e professor geral, tendo sido leitor e avaliador de textos de teologia. 
Ressaltando as agudezas dos discursos de Vieira e aplaudindo o engenho do autor, os censores se posicionavam com a distância necessária, integrando as circunstâncias da produção e da circulação do livro aos aparatos do decoro. Assim, essas aprovações valorizam a utilidade moral dos sermões de Vieira, os quais cumpriam de modo fino com as funções do gênero: persuadir os leitores, inculcar proposições morais na audiência e, a partir disso, intervir na prática cotidiana. Apesar de não ter construído uma teoria ou modelo de pregação, Vieira elaborou um "conjunto de tópicos em ordem a uma parenética pastoralmente frutuosa" (MENDES, 1989, p.21) e, a partir disso, seus sermões poderiam ensinar, pelo exemplo, aos pregadores a arte de pregar. Nesse sentido, as edições impressas dos sermonários disponibilizavam os discursos à imitação e ofereciam a autoridade de Vieira, tido como um grande pregador do mundo católico, para a emulação dos pregadores.

\section{COMENTÁRIO CONCLUSIVO}

Constantemente mencionadas na bibliografia, as edições madrilenas são lembradas pelas críticas elaboradas por Vieira. No entanto, a maior parte dos trabalhos que citam essas três edições desconsidera que elas compõem uma série de sermonários de autoria atribuída a Vieira impressos em Madrid. Ao buscarmos as três edições nos catálogos da Biblioteca Nacional da Espanha e da Biblioteca da Universidade Complutense de Madrid, encontramos dez volumes, sendo as demais sete: Quarta Parte (1680), Nova Primeira Parte (1680), Quinta Parte (1683), Sexta parte (1685), Sétima Parte (1687), Primeira Parte dos Sermões de Maria, Rosa Mystica (1688), Segunda Parte dos Sermões de Maria, Rosa Mystica (1689). No entanto, apesar da continuação da numeração, essas edições passaram a ser traduções integrais dos volumes da editio princeps, os quais eram remetidos por Vieira a Madrid.

A tensão entre Vieira e os livreiros madrilenos não evitou que o jesuíta permitisse que Gabriel de León financiasse e comercializasse os seus sermonários traduzidos da editio para o castelhano, ainda que tivesse quem os financiasse em Lisboa (VIEIRA, 1928, p.423). Em 1679, sendo o padre jesuíta Andrés Mendo o intermediador entre Vieira e León e contando com o auxílio de Duarte Ribeiro de Macedo para revisar as traduções (VIEIRA, 1928, p.424; p.651), León prosseguiu 
financiando as edições dos sermões de Vieira, impressos em Madrid, na década que se seguiu e, após seu falecimento, seus Herdeiros custearam as edições de Maria, Rosa Mística (1688 e 1689).

No entanto, na Espanha e na América hispânica, a demanda pelos sermonários de Vieira não se encerrou no século XVII. Entre 1711 e 1715, os sermões do pregador português foram novamente traduzidos e impressos em Madrid, em 14 tomos custeados por Francisco Pérez e 1 por Francisco Fernandez, e, em 1734, foram impressos 4 tomos em Barcelona, à custa de Juan Piferrer. Durante o século XVII e a primeira metade do XVIII, a aplicação dos sermonários de Vieira para a formação de pregadores fez-se presente em Portugal, na Espanha e nas conquistas. No entanto, no decorrer dos séculos, as leituras dos textos de Vieira passaram a ser enquadradas em diversos contextos sociais e situações comunicativas. No século XIX, à medida que a retórica foi suprimida, o mito da não ensinabilidade da escrita literária emergiu e ganhou força, sendo Antônio Vieira integrado aos cânones literários brasileiros e portugueses. A inserção de Vieira na instituição literária inseriu seus textos em situações diversas, muitas das quais distantes dos círculos religiosos. Em 31 de março de 1886, por exemplo, o periódico A mai de família publicou uma máxima atribuída a Vieira na Secção Pensamentos: "Palavras sem obras são tiros sem bala; atroam, mas não ferem. Padre Antonio Vieira" (VIEIRA, 1886, p.44). Desse modo, as formas de leitura e os sentidos atribuídos aos discursos de Vieira se transformaram ao passo que os contextos sociais em que eram inseridos se modificaram e, consequentemente, os leitores passaram a mobilizar esses textos de maneiras distintas.

Portanto, as formas com que um livro é lido estão associadas a como ele se apresenta ao mundo letrado, o que, por sua vez, relacionase às estratégias comerciais e políticas de produção e de circulação do texto e aos usos diferenciais do texto empregados pelos leitores. $\mathrm{O}$ fato das edições dos Sermones Varios serem direcionadas para a formação dos pregadores e se apoiarem no nome de Vieira, que já era considerado uma autoridade no e do púlpito, garantiram a legitimidade da produção e da circulação dos livros, bem como da continuação da numeração seriada naqueles que foram impressos após a publicação das críticas de Vieira.

Porfim, este trabalho demonstra que as polêmicas que envolveram 
analisadas como disputas ideológicas, uma vez que estavam inseridas numa complexa rede de interesses políticos e econômicos.

\section{REFERÊNCIAS}

ALVAREZ, Fernando J. Bouza. Portugal no tempo dos Filipes: política, cultura, representações (1580-1668). Lisboa: Edições Cosmos, 2000.

ANONYMOUS (1657?). La Villa de Madrid Corte de los Reyes Católicos de España. Amsterdam: Johannes Janssonius. Disponível em: http://bdh-rd.bne.es/ viewer.vm?id=0000017490. Acesso em 02 de Nov de 2019.

ANSELMO, Artur. Estudos de História do Livro. Lisboa: Guimarães Editores, 1997.

CAYUELA, Anne (1996). Le paratexte au siècle d'or. Genebra: Droz.

CERTEAU, Michel de (1998). A invenção do cotidiano: artes de fazer. Petrópolis: Vozes.

CHARTIER, Roger . El concepto de lector moderno. In: Historia de la edición y de la lectura en España. Madrid: Fundación Germán Sánchez Ruipérez, 2003.

. A mão do autor e a mente do editor. São Paulo: Ed. UNESP, 2014.

COBO, Mercedes Agulló. La imprenta y el comercio de libros em Madrid (siglos XVI - XVIII). (Tese de Doutoramento). Universidad Complutense de Madrid, Espanha, 1991.

CONSELHO DA INQUISIÇÃO. Libro cuarto de cartas del Consejo de Inquisición a los Tribunales de América. Madrid: Archivo Histórico Nacional de Madrid, fundo Inquisición, 355, f.312, 1664.

CONSELHO DA INQUISIÇÃO (1776). Édito Inquisitorial de 17 de março de 1776. Disponível em: http://hdl.handle.net/10347/9200. Acesso em 02.nov.2019.

CONSELHO DAS ÍNDIAS. Reales Cédulas, Reales Provisiones y Cartas Acordadas. Sevilla: Arquivo Geral das Índias, fundo Casa da Contratação, 5039, f.1, 1666.

CONTRERAS, Pedro de. Memorial do Pedro de Contreras, religioso do Colégio Imperial da Companhia de Jesus, em Aragão. Barcelona: Archivo de la Corona de Aragón, fundo Consejo de Aragón, legajo 0083, 1625.

DÍAZ, Manuel Peña (2003). "El comercio, la circulación y la geografía del libro". In: Historia de la edición y de la lectura en España. Madrid: Fundación Germán Sánchez Ruipérez, 2003.

ESPINOSA, Gabriel Sánchez. Los puestos de libros de las gradas de San Felipe de Madrid en el siglo XVIII". Goya, 2011.

FAJARDO, José del Rey. Los Jesuitas en Venezuela: Las misiones germen de la nacionalidad. Bogotá: Universidad Católica Andrés Bello, 2007.

GOMEZ, Fermín de los Reyes. El control legislativo y los Index inquisitoriales. In: Historia de la edición y de la lectura en España. Madrid: Fundación Germán Sánchez Ruipérez, 2003.

INFANTES, Víctor. "La lectura em España". In: Historia de la edición y de la lectura en España. Madrid: Fundación Germán Sánchez Ruipérez, 2003. 
; PEREIRA, Martínez Ana (2012). Los primeiros catálogos de libros editados em Madrid. Madrid: Turpin, 2012.

JARA, Álvaro. Fuentes para el estúdio de la Colonia: protocolos de los escribanos de Santiago. Santiago: Ediciones de Bibliotecas, Archivos y Museos, 1996.

LEÓN, Gabriel. Catalogo de los libros que tiene Gabriel de León, Mercader de Libros en esta Corte 1688. In: Los primeiros catálogos de libros editados en Madrid. Madrid: Turpin, 2012.

LEÓN, Gabriel. Memoria ajustada de los libros que Gauriel de León, mercader de libros, vezino desta Corte, remite a su hijo Pedro de León a la ciudad de Lima 1697. In: La imprenta y el comercio de libros em Madrid (siglos XVI - XVIII). (Tese de Doutoramento). Universidad Complutense de Madrid, Espanha. p.302, 1991.

MENEZES, Luís Duarte de. Delação de Duarte Luís de Menezes, Conde de Tarouca. In: Del escribano a la biblioteca: La civilización escrita europea en la Alta Edad Moderna (siglos XV-XVII). Madrid: Síntesis, 1997.

MENDES, Margarida Vieira. A oratória barroca de Vieira. Alfragide: Editorial Caminho, 1989.

MOLL, Jaime. De impressores y libreros: un pleito de 1651. In: Problemas bibliográficos del libro del Siglo de Oro. Alicante: Biblioteca Miguel de Cervantes, 2013.

VALE, Padre del. Cartas ao Procurador Geral de Portugal. Lisboa: Arquivo Nacional da Torre do Tombo, fundo Cartório dos Jesuítas, maço 0069, documento 237, 1674.

VIEIRA, Antonio. Cartas: Tomo III. Coimbra: Imprensa da Universidade, 1928.

p.44. (1886, Março 31). Pensamentos. A mai de familia, 6, aspx?bib $=341703 \&$ PagFis $=1181 \&$ Pesq $=\% 22$ Antonio $\% 20$ Vieira $\% 22$ Acesso em 03.Mar.2017

. Sermones Varios del Padre Antonio de Vieyra, de la Compañia de Jesus. Madrid: Pablo do Val, 1662.

Sermones Varios del Padre Antonio de Vieyra, de la Compañia de Jesus. Madrid: Joseph Fernandez de Buendia, 1664. Disponível em: https://www.encurtador. com.br/ftAT2. Acesso 07.Nov.2018.

Sermones Varios del Padre Antonio de Vieyra, de la Compañia de Jesus. Madrid: Joseph Fernandez de Buendia, 1664. Disponível em: https://www.encurtador. com.br/dopr8. Acesso em 07.Nov.2018.

Sermones Varios del Padre Antonio de Vieyra, de la Compañia de Jesus: Tomo segundo. Madrid: Antonio Gonçalez de Reyes, 1678. Disponível em: https:// www.encurtador.com.br/jBKQ3. Acesso em 07.Nov.2018.

. Sermones Varios del Padre Antonio de Vieyra, de la Compañia de Jesus: Tomo terceiro. Madrid: Antonio Francisco de Zafra, 1678. Disponível em: https:// www.encurtador.com.br/ehuyE. Acesso em 07.Nov.2018.

Sermoens do p.Antonio Vieira, da Companhia de Jesu, Pregador de Sua Alteza: Primeyra Parte. Lisboa: Oficina de Joam da Costa, 1679. Disponível em: htts://www.http://purl.pt/297. Acesso em 07.Nov.2018. 
REVISTA DO PROGRAMA DE PÓS-GRADUAÇÃO EM COMUNICAC̨ÃO, LINGUAGENS E CULTURA DA UNIVERSIDADE DA AMAZÔNIA

Recebido em 05 Out 2019 | Aprovado em 15 Nov 2019

Ana Elisa Silva AREDES

Doutoranda em História pela Faculdade de Letras da Universidade do Porto. É mestre em História Social pelo Programa de Pós-Graduação em História Social da Universidade Federal do Rio de Janeiro. Nessa Universidade, obteve os graus de Bacharel e Licenciada em História. Por meio da abordagem interdisciplinar que envolve os campos da História e dos Estudos Literários, desenvolve pesquisas com temas relacionados ao funcionamento da oratória de padre Antônio Vieira e das práticas letradas no Período Moderno. E-mail: anaelisaarede@gmail.com. 